\title{
Grammar trumps lexicon: Typologically inconsistent weight effects are not generalized*
}

\author{
Guilherme D. Garcia \\ McGill University
}

\section{Introduction}

Recent studies have shown that not all patterns in one's lexicon are generalized to novel words (Hayes \& Londe 2006, Carpenter 2010, Becker et al. 2011, Becker et al. 2012, Jarosz 2016). These studies evidence that the grammar does not necessarily reflect the lexicon, given that unnatural patterns tend to be harder to learn. One example involves laryngeal alternations in English (Becker et al. 2012). In the English lexicon, such alternations are more commonly found in monosyllables (knife $\rightarrow$ knives) than in polysyllables. This violates INITIAL-SYLLABLE FAITHFULNESS, a cross-linguistic tendency to protect wordinitial syllables (Steriade 1994, Beckman 1997). Native speakers, however, seem to equally favor monosyllables and polysyllables in a wug test, which suggests that their grammars deviate from the expected lexical patterns. Alternatively, this could also mean that the effect in the grammar is not as robust as it is in the lexicon, and is therefore harder to detect. The present paper provides further evidence that typologically marked patterns are less likely to be generalized by the grammar. The example comes from weight effects on stress in Portuguese.

Weight-sensitive languages present a correlation between syllable weight and stress, insofar as heavy syllables attract stress (Gordon 2006, Goedemans \& van der Hulst 2013). This correlation is further reinforced by the phonetics, given that heavy syllables tend to be longer, and stress is often correlated with duration (Gordon 2004). Stress in Portuguese, for example, is correlated with duration (Major 1985), and, as in English, is sensitive to weight. In this language, however, weight effects on antepenultimate syllables have been shown to be negative (Garcia 2017), an observation which, taken in isolation, contradicts the typology of weight, as heavy syllables should not repel stress.

In this paper, I show that even though a negative weight effect exists in the Portuguese lexicon, native speakers do not generalize such an effect. Rather, speakers 'repair' the

*Thanks to Heather Goad, Morgan Sonderegger, Natália B. Guzzo and John Kruschke for numerous suggestions. Thanks also to the audience and reviewers of NELS 47. 


\section{Guilherme D. Garcia}

weight effect in question, and favor antepenultimate stress on heavy antepenultimate syllables more frequently than on light antepenultimate syllables. The paper is organized as follows: In section 2, I briefly review the weight patterns found in the Portuguese lexicon. In section 4, I describe the experimental design employed in the present study, which aims to investigate to what extent native speakers' grammars capture the negative lexical pattern alluded to above. In sections 5 and 6, I model the data and discuss the results.

\section{Weight gradience in Portuguese}

Traditional approaches to weight and stress tend to assume a categorical notion of weight (e.g., Hyman 1985). In other words, syllables are either light (L) or heavy (H). Indeed, even though ternary weight distinctions exist, most weight-sensitive languages show a binary distinction (Gordon 2006). Portuguese is one such language, as weight effects in the language have traditionally been treated as binary. One implication of a binary weight distinction is that a given heavy syllable cannot be heavier than another heavy syllable.

Besides a binary weight distinction, previous studies on Portuguese weight effects have also assumed that weight only directly impacts stress in word-final syllables (Bisol 1992, Collischonn 2010, Lee 2007, Wetzels 2007). In other words, within the trisyllabic stress window in the language, the weight of penultimate and antepenultimate syllables is not assumed to affect the likelihood of penultimate and antepenultimate stress, respectively. In fact, this observation is at the core of the main stress rule in Portuguese nouns and adjectives, ${ }^{1}$ shown in (1)—where $\mathrm{X}$ stands for either a light or a heavy syllable.

Regular stress rule in Portuguese: XXH́ else XX́L

a. Stress is final if the final syllable is heavy

b. Otherwise, stress is penultimate

papél 'paper'

sapáto 'shoe'

The rule in (1) accounts for over 70\% of the Portuguese Lexicon (Garcia 2014). The remaining words are traditionally classified as irregular, and are summarized in (2). Note that all words with antepenultimate stress (12\% of the lexicon) are deemed to be exceptional. The remaining two cases of irregular stress consist of XX́H words (11\%) and XXL words $(3 \%)$ - I return to this difference in lexical proportion in section 5.

Irregular stress in Portuguese

a. Antepenultimate stress (X́XX)

b. Penultimate stress if final syllable is heavy $(\mathrm{XX} H)$

c. Final stress if final syllable is light (XXĹ)

fanático 'fanatic' fácil 'easy'

jacaré 'alligator'

In a previous study (Garcia 2017), I show that weight effects are not binary, and do not only directly affect word-final syllables. Instead, stress on all three syllables in the stress

\footnotetext{
${ }^{1}$ Stress on Portuguese verbs is morphologically determined; see Wetzels (2007).
} 
domain is sensitive to weight. In other words, if we examine a comprehensive lexicon (the Portuguese Stress Lexicon; Garcia 2014), we find that the two main assumptions about Portuguese weight effects are not empirically accurate.

One important characteristic of the Portuguese lexicon examined in Garcia (2017) is that weight in antepenultimate syllables is negatively correlated with antepenultimate stress: ĹLL words are more common than HLL words, which in turn indicates that heavy antepenultimate syllables repel stress in the lexicon. Taken in isolation, this observation contradicts the typology of weight. A possible explanation for this asymmetrical weight pattern, however, may lie in metrical optimization, which I discuss next.

\subsection{Footing and weight}

One reason why ĹLL words are more frequent in the Portuguese lexicon than H́LL words could be the different metrical structures involved in each of these word types. Most footbased analyses in Portuguese assume that the language builds moraic trochees (e.g., Bisol 1992). If that is the case, then LLL words could be parsed as (LL) $\langle\mathrm{L}\rangle$ - extrametricality is in fact assumed in Bisol (1992) for all words with antepenultimate stress. HLL words, on the other hand, could be parsed as $(\mathrm{H}) \mathrm{L}\langle\mathrm{L}\rangle$, which results in an unparsed syllable in the middle of the word, or (HL) $\langle\mathrm{L}\rangle$, which results in an uneven trochee. Either way, HLL words yield a more marked metrical structure, which could explain why heavy syllables in antepenultimate syllables are not stress-attracting relative to light syllables in the same position. In other words, weight would be constrained by the footing involved in the language.

The preference for a light stressed syllable is in fact found in other languages. One example is Fijian (Hayes 1995), where some stressed syllables shorten to allow for a more complete parse of the word into metrical feet. This is a case of Trochaic Shortening (Hayes 1995, p. 146), a process which could explain what is observed in the Portuguese lexicon. However, as shown in Garcia \& Goad (2017), it is highly unlikely that Portuguese actually builds feet. First, if Portuguese indeed builds binary feet (moraic trochees), then we would expect lexical words to be at least bimoraic, assuming that all Prosodic Words must contain at least one foot (Selkirk 1984, Nespor \& Vogel 1986), McCarthy \& Prince 1995). However, subminimal words (i.e., monomoraic) not only exist in the lexicon, but are also productive in hypocoristics, for example. Second, truncated forms can yield both iambs or trochees-even the same word can lead to truncated forms where footing is ambiguous: profissionál, for example, can be truncated as profí and as profíssa. Third, we observe the same ambiguity in first language acquisition data (Ferreira-Gonçalves 2010).

Given the observations above, it is not surprising that different foot-based analyses in the language have assumed multiple foot types and additional mechanisms to account for the patterns observed in Portuguese: trochees (Bisol 1992), iambs as well as trochees (Ferreira-Gonçalves 2010, Lee 2007), and dactyls as well as trochees (Wetzels 1992). Crucially, as we will see in section 5, native speakers do not generalize the negative weight effect in the lexicon. Instead, they favor stress on heavy syllables in all positions in the 


\section{Guilherme D. Garcia}

stress domain, an observation that further strengthens the argument that Portuguese has no feet. $^{2}$

The negative effect in the lexicon, captured by Trochaic Shortening, could indicate that feet used to play a role in the language, but that role is no longer productive. One important question, however, is why a negative weight effect is not found in penultimate syllables in the Portuguese lexicon as well, given that word-final syllables in the language are generally not assumed to be extrametrical (unlike in English). As a result, parsing LH́L also yields an unfooted syllable - and the only context in which a syllable has been assumed to be extrametrical in Portuguese is when stress falls on the antepenultimate syllable, as mentioned above.

\section{Objectives}

The objective of the present study is to examine whether native speakers generalize the weight gradience found in the Portuguese lexicon and, crucially, whether they generalize the negative weight effect found in antepenultimate syllables. In the next section, I turn to the methods employed to answer these questions.

\section{Methods}

The first step towards examining the questions above was to determine the reliability of the negative weight effects in antepenultimate syllables. We assume that individual speakers' lexica are smaller than the set of all existing words in the language - the lexicon modelled in Garcia (2017) contained 154,610 words (non-verbs). If the negative effect in question stems from groups of uncommon words at the periphery of the lexicon, then it is possible that speakers rarely encounter such words. To confirm that the effects discussed above are robust and can be found across the entire lexicon, 10,000 models (binomial logistic regressions) were run in $\mathrm{R}$ ( $\mathrm{R}$ Core Team 2017), each of which examined the effect of a heavy antepenultimate syllable on antepenultimate stress. Each model was based on a random subset of the entire lexicon. Each of the 10,000 subsets contained 10,000 words, and therefore represented a conservative estimate of a more realistic lexicon size.

Once all 10,000 models are run, we can examine the distribution of effect sizes (in logodds) involving heavy antepenultimate syllables. In other words, we are interested in the log-odds of antepenultimate stress in HLL words relative to LLL words. I will refer to a heavy antepenultimate syllable as $\mathrm{H}_{3}$, and to the effect size of $\mathrm{H}_{3}$ as $\hat{\beta}_{H_{3}}$. Heavy penultimate and final syllables will be represented as $\mathrm{H}_{2}$ and $\mathrm{H}_{1}$, respectively, given their position in the trisyllabic stress window in Portuguese-counting from the right edge of the word.

In (3), we can see that nearly all simulations ${ }^{3}$ yield the same result: antepenultimate stress is less likely in HLL words relative to LLL words. The dark bar at the bottom of (3) demarcates the $95 \%$ most frequent effect sizes found across all 10,000 simulations-

\footnotetext{
${ }^{2}$ The discussion of whether Portuguese builds feet is beyond the scope of this paper, and is developed in detail in Garcia \& Goad (2017).

${ }^{3}$ If we only consider the simulations where the effect of $\mathrm{H}_{3}$ is significant at $\alpha=0.05$, then the entire distribution is negative.
} 
all of which are negative, indicating that the presence of a heavy antepenultimate syllable $\left(\mathrm{H}_{3}\right)$ lowers the log-odds of antepenultimate stress. The mode of the distribution of $\hat{\beta}_{\mathrm{H}_{3}}$ is -0.187 . In other words, in the presence of a heavy antepenultimate syllable $\left(\mathrm{H}_{3}\right)$, the odds of antepenultimate stress are lowered by a factor of $1.2(\exp (0.187))$.

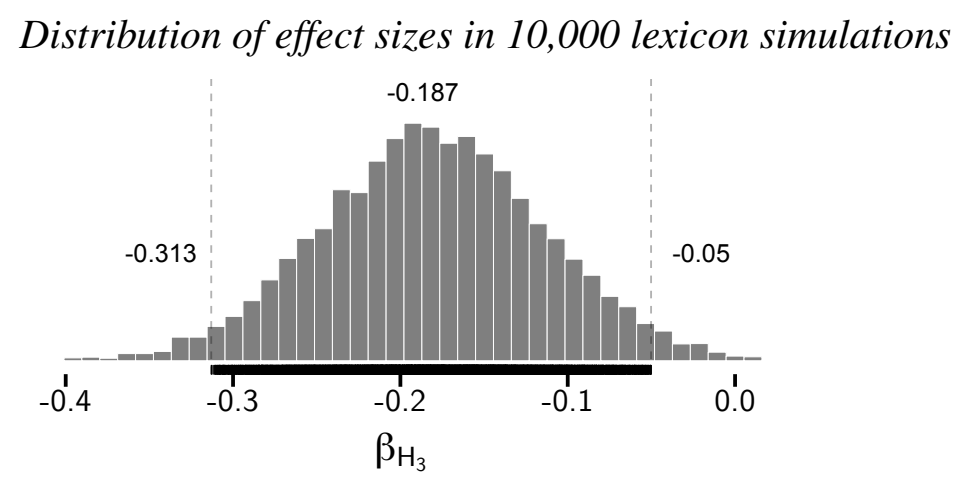

Another method of testing the reliability of the negative effects of $\mathrm{H}_{3}$ involves modelling only frequent words in the lexicon. Presumably, these words accurately approximate speakers' lexica. Such a model was run based on the frequency corpus developed by Tang (2012), and the same negative effect was found. In fact, the mode of the distribution of effect sizes is even lower when only frequent words are modelled: -0.28 .

We can therefore conclude that the negative effect in question is not restricted to a comprehensive lexicon. Rather, this effect is robust in the language-however one decides to model it. Next, I turn to the experimental design to test whether speakers in fact generalize the negative effect of antepenultimate heavy syllables.

\subsection{Experimental design}

A force-judgement task was designed where participants were auditorily presented with minimal pairs of nonce words. Participants were then asked to choose which of the two versions in each pair sounded more natural to them. They were explicitly told that none of the words existed in the language, and that all words were supposed to refer to objects, not actions or qualities. To enforce a noun interpretation, all nonce words were preceded by a definite article ( $o, a$, 'the (masc, fem)'). The stimuli were recorded by a female native speaker of Brazilian Portuguese with training in linguistics.

Each minimal pair used in the experiment differed solely with regard to stress-for example, o bámesil vs. o bamésil. All nonce words $(N=240)$ were developed using an $\mathrm{R}$ (R Core Team 2017) script (Garcia 2015), and later checked for phonotactic naturalness by sorting the items according to their bigram probability-using the lexicon in Garcia (2014) as the baseline.

The stimuli were categorized into four weight profiles, namely, HLL, LHL, LLL and LLH. LLH words were used as the control condition, given that word-final weight effects are well-established in the literature-as per (1). For these words, participants heard final and penultimate stress. The prediction is that final stress should be preferred. LLL words 


\section{Guilherme D. Garcia}

were used as the baseline against which HLL and LHL words could be compared. For these three groups of words, participants heard antepenultimate and penultimate stress. If native speakers mirror the patterns found in the Portuguese lexicon (Garcia 2017), then the prediction in these cases is that antepenultimate stress should be disfavored in both HLL and LHL words relative to LLL words. The order of presentation was randomized on the basis of stress patterns and weight profiles. Finally, segmental quality was randomly varied for onsets, vowels, and codas.

\subsection{Participants}

All participants ( $n=27 ; 15$ female) were native speakers of Brazilian Portuguese, some of whom were living in Montreal at the time of the experiment. Speakers had different levels of proficiency in foreign languages, including English, French and Spanish-but no participant was bilingual from birth. The mean age of the sample was 30, and almost all speakers had a university degree. A pre-test was designed to ensure that participants were able to perceive where stress is located in different words, and no difficulties were foundthis is unsurprising, given that Portuguese stress is saliently signalled (Major 1985).

\section{Analysis}

Unlike the 10,000 lexicon simulations discussed above, which made use of simple logistic regressions, the experimental data in the present study were analyzed using Bayesian hierarchical logistic regressions. The models were run using JAGS (Plummer 2003) in R. One regression modelled the probability of antepenultimate ( $v s$. penultimate) stress in the following weight profiles: LLL, HLL and LHL. Another regression modelled the probability of penultimate ( $v s$. final) stress in LLH words. In both cases, a by-speaker random intercept was added. Because each model predicted the log-odds of a given stress pattern on the basis of weight, the regression modelling LLH words was an intercept-only model.

The results are plotted in (4). On the $y$-axis, we can see the overall preference (in \%) for a particular stress position, indicated along the $x$-axis $(\mathrm{APU}=$ antepenultimate; $\mathrm{PU}$ = penultimate; $\mathrm{U}=$ final) - standard error bars are also shown. As expected, participants favored final stress (U) over penultimate stress (PU) in LLH words. This is consistent with the rule in (1). In LHL words, participants favored penultimate stress over antepenultimate stress (APU), as predicted. This is consistent with the fact that antepenultimate stress is rare in the language if a heavy penultimate syllable is present. 


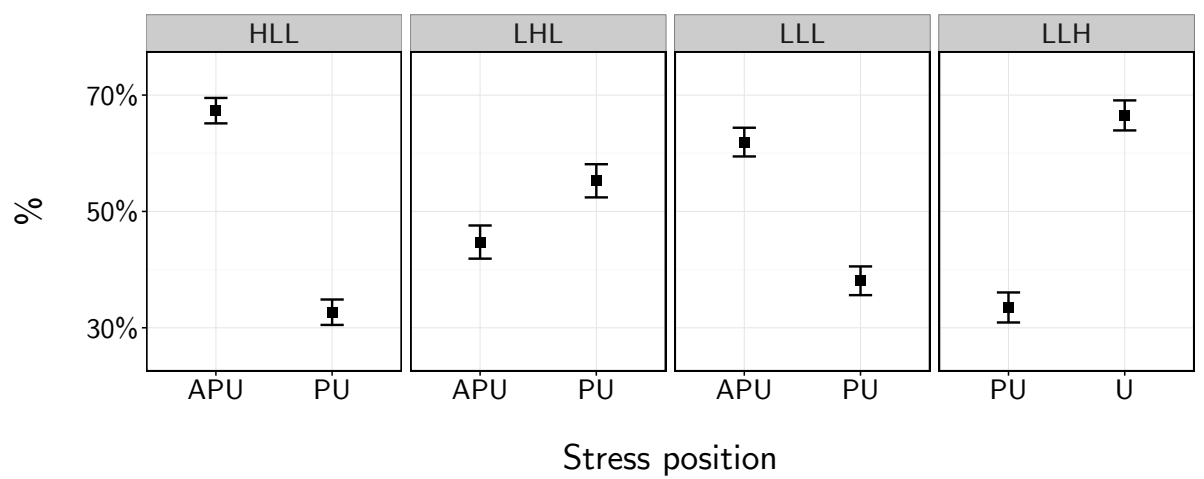

Importantly, we can see in (4) that participants favored antepenultimate stress in HLL words and LLL words. Note, however, that antepenultimate stress was more frequently chosen as the more natural pattern in HLL words relative to LLL words. If this is statistically credible once we take into account by-speaker variation, this means that speakers do not generalize the negative effect of $\mathrm{H}_{3}$ in the lexicon.

In (5), we can visualize the posterior distributions of the weight effects in question. The effects are presented as follows: $\mathrm{H}_{3}$ represents the effect of a heavy syllable in antepenultimate position. In other words, the distribution in ?? refers to the credible log-odds of choosing antepenultimate stress in HLL vs. LLL words. ?? refers to the credible log-odds of choosing penultimate stress in LHL vs. LLL words. Finally, ?? refers to the credible logodds of choosing final stress over penultimate stress in LLH words (intercept-only model).

Posterior distributions with associated mode and HDIs for $\mathrm{H}_{1-3}$
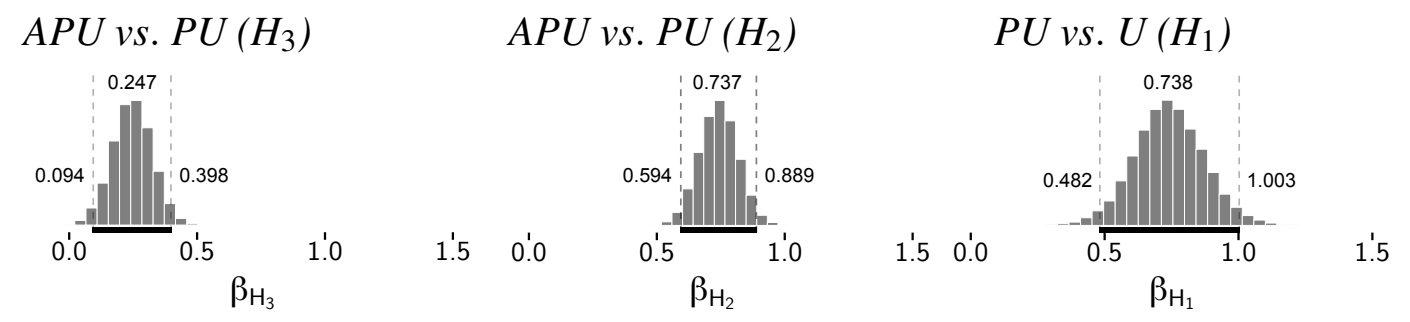

The histograms in (5) represent the most credible $\hat{\beta}$ values for each heavy syllable in the stress domain. The dark bar at the bottom of each plot (as well as the dashed vertical lines) demarcates the $95 \%$ highest density intervals (HDI). These are the $95 \%$ most credible parameter values given the data in (4). ${ }^{4}$ The mode of each distribution is also provided (between the dashed lines). Note that all modes and all HDIs exclude zero, which indicates that the statistical effects in question are all credible and robust. Crucially, all the posterior distributions in question are positive, including the distribution of $\mathrm{H}_{3}$, confirming that a heavy antepenultimate syllable increases the odds of antepenultimate stress (by a

\footnotetext{
${ }^{4}$ Not to be confused with frequentist confidence intervals, which do not represent a probability distribution of credible values given the data.
} 


\section{Guilherme D. Garcia}

factor of 1.28). In other words, speakers' behavior vis-à-vis antepenultimate weight effects contradicts what we find in the lexicon.

\section{Discussion}

The data examined above show that the weight distinction in Portuguese is not binary or categorical. Rather, weight is generalized to novel words in a gradient manner, which mirrors the lexical patterns shown in Garcia (2017) for the Portuguese lexicon. This is clear if we compare the effect of a heavy penultimate syllable $\left(\mathrm{H}_{2}\right)$ with the effect of a heavy antepenultimate syllable $\left(\mathrm{H}_{3}\right)$. Even though the effect of a heavy final syllable $\left(\mathrm{H}_{1}\right)$ cannot be directly compared to $\mathrm{H}_{2,3}$, given the distinct stress options in question, it is safe to assume that $\mathrm{H}_{1}$ is more robust than both $\mathrm{H}_{2}$ and $\mathrm{H}_{3}$-recall that previous weight-based approaches to Portuguese have assumed that weight-sensitivity is only directly observed in word-final syllables (1). As a result, we can assume the following positional weight gradience for Portuguese: $\mathrm{H}_{1}>\mathrm{H}_{2}>\mathrm{H}_{3}$. In other words, weight effects are gradient and weaken monotonically as we move away from the right edge of the word-a positional effect which mirrors what is found in the Portuguese lexicon (Garcia 2017).

The experimental results above also show that the negative effect of $\mathrm{H}_{3}$ in the lexicon is, in fact, positive when speakers' generalize weight effects to novel words. As a result, if the negative effect in the Portuguese lexicon is the result of metrical optimization (e.g., Trochaic Shortening in Fijian discussed above), speakers' behavior require a different explanation. ${ }^{5}$

Note that the posterior distribution of $\mathrm{H}_{1}$ is wider than the distributions of $\mathrm{H}_{2}$ and $\mathrm{H}_{3}$. In other words, $\mathrm{H}_{1}$ has a stronger effect (i.e., a higher $\hat{\beta}$ value), but it also has a higher level of uncertainty. This makes intuitive sense if we revisit the irregular patterns presented in (2). As we saw above, besides antepenultimate stress (X́XX), the other two irregular stress patterns in Portuguese consist of XX́H and XXĹ. We also saw that the former pattern is by far more frequent than the latter in the lexicon (Garcia 2017), which indicates that not all 'exceptional' patterns are equally exceptional. Interestingly, what the wider distribution of $\mathrm{H}_{1}$ suggests is that speakers are sensitive to this patterned exception in the lexicon, and therefore assign a higher level of uncertainty to their responses involving LLH words. As a result, their generalization of $\mathrm{H}_{1}$ effects mirrors what is observed in the lexicon.

\section{Conclusion}

We have seen that weight in Portuguese cannot be classified as binary or categorical. The empirical data examined above indicate that speakers' generalizations of weight effects are modulated by the location of a given heavy syllable in the stress domain: the farther a given syllable is from the right edge of the word, the weaker its weight effect on stress is. This positional effect has also been observed in the Portuguese lexicon (Garcia 2017), where weight effects monotonically weaken as we move away from the word-final sylla-

\footnotetext{
${ }^{5}$ See Garcia \& Goad (2017).
} 
ble. In summary, the lexicon and the grammar are consistent vis-à-vis weight gradience in Portuguese.

The data examined in this paper have also revealed that, even though Portuguese speakers generalize the weight gradience present in their language, they do not generalize the negative weight effect found in antepenultimate syllables. Speakers learn the opposite pattern instead, and assign a positive effect to heavy antepenultimate syllables. This shows that speakers may not only underlearn an unnatural phonological pattern in their lexicon (e.g., Hayes et al. 2009, Becker et al. 2012), but they can also repair such a pattern in novel words. The result, as we have seen, is that all syllables in the stress domain present weight effects-which is what we would expect in a weight-sensitive language where weight is the primary predictor of the location of stress.

\section{References}

Becker, Michael, Nihan Ketrez, \& Andrew Nevins. 2011. The surfeit of the stimulus: Analytic biases filter lexical statistics in Turkish laryngeal alternations. Language 87:84125.

Becker, Michael, Andrew Nevins, \& Jonathan Levine. 2012. Asymmetries in generalizing alternations to and from initial syllables. Language 88:231-268.

Beckman, Jill. 1997. Positional faithfulness, positional neutralization, and Shona vowel harmony. Phonology 14:1-46.

Bisol, Leda. 1992. O acento e o pé métrico binário. Cadernos de Estudos Lingüísticos 22:69-80.

Carpenter, Angela C. 2010. A naturalness bias in learning stress. Phonology 27:345-392.

Collischonn, Gisela. 2010. O acento em português. In Introdução a estudos de fonologia do português brasileiro, chapter 4, 132-165. Porto Alegre: EDIPUCRS, 5th edition.

Ferreira-Gonçalves, Giovana. 2010. Aquisição prosódica do português: o acento em suas formas marcadas. Revista Virtual de Estudos da Linguagem (ReVEL) 8:61-81.

Garcia, Guilherme D. 2014. Portuguese Stress Lexicon. Comprehensive list of non-verbs in Portuguese. Available at http://guilhermegarcia.github.io/psl.html.

Garcia, Guilherme D. 2015. Word generator: an $R$ script for generating nonce words.. Commented code available at http://guilhermegarcia.github.io/resources. html.

Garcia, Guilherme Duarte. 2017. Weight gradience and stress in Portuguese. Phonology 34:41-79. Project materials available at http://guilhermegarcia.github.io/ garcia2017.html.

Garcia, Guilherme Duarte, \& Heather Goad. 2017. Stress without feet: a parametric distinction between Portuguese and English. Unpublished manuscript.

Goedemans, Rob, \& Harry van der Hulst. 2013. Weight factors in weight-sensitive stress systems. Leipzig. Available at http://wals. info/chapter/16.

Gordon, Matthew. 2004. Syllable weight. In Phonetically based phonology, ed. Bruce Hayes, Robert Kirchner, \& Donca Steriade, chapter 9, 277-312. New York: Cambridge University Press. 


\section{Guilherme D. Garcia}

Gordon, Matthew. 2006. Syllable weight: phonetics, phonology, typology. New York: Routledge.

Hayes, B. 1995. Metrical Stress Theory: Principles and Case Studies. Chicago: University of Chicago Press.

Hayes, Bruce, \& Zsuzsa Cziráky Londe. 2006. Stochastic phonological knowledge: The case of Hungarian vowel harmony. Phonology 23:59-104.

Hayes, Bruce, Péter Siptár, Kie Zuraw, \& Zsuzsa Londe. 2009. Natural and unnatural constraints in Hungarian vowel harmony. Language 85:822-863.

Hyman, Larry. 1985. A theory of phonological weight. Dordrecht: Foris Publications.

Jarosz, Gaja. 2016. Defying the stimulus: acquisition of complex onsets in Polish. Unpublished manuscript.

Lee, Seung-Hwa. 2007. O acento primário no português: uma análise unificada na Teoria da Otimalidade. In $O$ acento em português: abordagens fonológicas, ed. Gabriel Antunes Araújo, 120-143. São Paulo: Parábola.

Major, Roy C. 1985. Stress and rhythm in Brazilian Portuguese. Language 61:259-282.

McCarthy, John J., \& Alan Prince. 1995. Prosodic morphology. In The handbook of phonological theory, ed. John A. Goldsmith, 318-366. Cambridge, MA, and Oxford, UK: Blackwell.

Nespor, Marina, \& Irene Vogel. 1986. Prosodic phonology. Dordrecht: Foris.

Plummer, Martyn. 2003. JAGS: A program for analysis of Bayesian graphical models using Gibbs sampling.

R Core Team. 2017. R: A language and environment for statistical computing. R Foundation for Statistical Computing, Vienna, Austria. URL http://www .R-project.org/.

Selkirk, Elisabeth. 1984. Phonology and syntax: the relation between sound and structure. Cambridge: MIT Press.

Steriade, Donca. 1994. Positional neutralization. Unpublished manuscript. Los Angeles: University of California, Los Angeles.

Tang, Kevin. 2012. A 61 million word corpus of Brazilian Portuguese film subtitles as a resource for linguistic research. UCL Working Papers in Linguistics 24: 208-214 .

Wetzels, W. Leo. 1992. Mid vowel neutralization in Brazilian Portuguese. Cadernos de Estudos Linguísticos 23:19-55.

Wetzels, W. Leo. 2007. Primary word stress in Brazilian Portuguese and the weight parameter. Journal of Portuguese Linguistics 5:9-58.

Guilherme D. Garcia

guilherme.garcia@mail.mcgill.ca 